\title{
PINEALOMA WITH A SOLITARY SPINAL METASTASIS
}

\author{
BY
}

\author{
FRANK R. MAGAREY and H. R. I. WOLFE \\ From the Welsh National School of Medicine, Cardiff
}

In forty-two cases of tumours of the glioma group giving rise to metastases, Polmeteer and Kernohan (1947) found only one pinealoma. In this case, which is recorded in detail by Bagenstoss and Love (1939), the tumour filled the third ventricle and had become implanted in the other ventricles and on the roots of most of the cranial nerves. The spinal cord was not examined. These authors also describe a second case in which a tumour having the cytological structure of a pinealoma was found at operation behind the optic chiasma. Fourteen months later laminectomy at the level of the twelfth dorsal vertebra revealed intra- and extramedullary tumours, two of which were examined histologically and showed a structure similar to that of the original tumour. It was not stated whether the presence of a tumour in the region of the pineal gland was ever proved in this case. There are several other instances in which pinealomas have given rise to metastases in the ventricles or around the base of the brain. Horrax and Bailey (1925) described three cases but in only one was the structure that of an adult type of pinealoma, and this showed implants limited to the third ventricle. Fulton and Bailey (1929) record another in which there were deposits in the ventricles and partial destruction of the pituitary gland and infundibulum by tumour infiltration. Berblinger (quoted by Bagenstoss and Love), reported a case of a pinealoma with metastases in the spinal cord and cauda equina.

Friedman and Plaut (1935) describe a case in which there was diffuse infiltration throughout the meninges, cranial and spinal nerves, and ganglia by large and medium sized cells without stroma, and at the site of the pineal gland there was a nodule the size of a pea which was found histologically to consist of the same type of cell as that in the other tumour masses. Neither in the so-called primary tumour nor in the metastases was the usual mixture of two types of cell seen, and it appears to us that the origin in the pineal gland, although suggestive, is not definitely proven. Ford and Muncie (1938) saw three cases of diffuse tumour infiltration of the ependyma of the third ventricle which histologically somewhat resembled a pinealoma with large and small cells, but in each case the pineal gland was normal. Stringer (1933) described a solitary implant in the tuber cinereum but the spinal cord was not examined.

We can find no record of a previous case of pinealoma in which there was a large solitary spinal metastasis, and we believe our case also to be unique in that the deposit formed a dumb-bell tumour.

\section{Case Report}

A healthy-looking dockyard worker aged 31, was admitted on May 30,1948, to the Surgical Unit of the Cardiff Royal Infirmary, under the care of Professor Lambert Rogers. The patient had been well until three years previously, when he began to have attacks of aching pain over the tip of the left shoulder. These attacks, lasting for hours or days, were followed by periods of remission of several weeks or months. During the latter part of March, 1948, the pain in the left shoulder became more severe, radiating to the lower cervical region, across to the tip of the right shoulder, and down the outer side of the left arm. About six weeks later he noticed that he could not move his left arm as well as usual, and within a few days the arm became paralysed, so that on May 20 he was admitted to another hospital suspected of suffering from anterior poliomyelitis. Four days later he had developed weakness of his left leg, and he was transferred to the Cardiff Royal Infirmary with the provisional diagnosis of spinal-cord tumour.

On examination a firm elliptical mass could be palpated at the base of the left anterior triangle of the neck. The long diameter of the tumour lay in the direction of the brachial plexus, and the mass was slightly movable from side to side but not up and down.

The muscles of the left arm and hand were wasted, the tendon reflexes were diminished, and voluntary movements were greatly reduced. There was loss of power in the biceps, in the flexors and extensors of the wrist and fingers, in the triceps, and in the small muscles of the hand. There was bilateral loss of pain sensibility below the level of the wrists and of temperature sensibility below both elbows.

Below the level of the cutaneous distribution of the second dorsal nerve there was a right-sided hemianæsthesia for pain and temperature but no loss of deep or tactile sensation. The left leg showed spastic paresis and an extensor plantar response, that of the right foot 
being equivocal. The cranial nerves were intact and there was no papillœdema.

By lumbar puncture the cerebrospinal fluid was found to be at a pressure less than atmospheric. The Queckenstedt response was sluggish, and there was a marked plateau on release of jugular compression. The fluid was clear and colourless and contained 30 lymphocytes per c.mm. and $75 \mathrm{mg}$. of protein per $100 \mathrm{c.cm}$. The Lange colloidal gold test was normal and the Wassermann reaction negative. An $x$-ray examination of the cervical spine showed slight enlargement of the fourth intervertebral foramen.

During the first week in hospital a flaccid paresis of the right arm developed, and on the tenth day the patient suddenly became cyanosed and had great difficulty in breathing, the temperature rising to $102^{\circ} \mathrm{F}$. and the pulse rate to 120 per minute. The intercostal muscles were found to be paralysed and he was placed in a mechanical respirator.

Operation (Performed by H.R.I.W.).-With the patient in the iron lung, anæsthesia was induced with cyclopropane, and the patient transferred to the operating table, where controlled anæsthesia was maintained and cervical laminectomy performed. A tumour was felt within the dural envelope at the level of the fourth and fifth cervical vertebræ, and there was a small soft extradural extension at the level of the fourth cervical nerve root. When the dura was opened an elliptical soft maroon-coloured tumour; approximately $4 \mathrm{~cm}$. long and $1 \mathrm{~cm}$. thick, was exposed. This tumour, which was very hæmorrhagic, was adherent to the dura and to the lateral aspect of the spinal cord, the latter being compressed and displaced towards the right. The spinal roots disappeared into the tumour substance. A small piece was removed for biopsy, a wide decompression performed, the dural tube sealed with "Gelfoam," and the wound closed in layers.

The patient's condition remained critical throughout the operation and no improvement followed decompression. He died shortly after being transferred from the operating table back to the iron lung.

Necropsy Findings.-The brain showed no evidence of increased intracranial pressure. There were no medullary or tentorial pressure cones. The pineal gland could not be identified but was replaced by a soft, well circumscribed greyish-pink tumour which was about $3 \mathrm{~cm}$. in diameter and which did not invade any surrounding structures (Fig. 1). There were a few petechial hæmorrhages on the floor of the fourth ventricle.

In the spinal canal there was a little blood in the subarachnoid space, and at the level of the bodies of the third, fourth, and fifth cervical vertebræ there was a fusiform greyish-pink tumour lying mainly subdural and partly extradural, lateral to the spinal cord on the left side (Fig. 2). This tumour was in close proximity to the spinal nerves and was continuous through the fourth cervical intervertebral foramen by a broad pedicle to a further extension of the growth in the form of a rounded mass about $4 \mathrm{~cm}$. in diameter (Fig. 3), which lay just anterior to the lateral spinous processes, giving rise to a well-defined dumb-bell-shaped tumour. This latter por으 tion of the tumour corresponded in position to the palpable mass in the neck which was detected clinicallyE

In the heart there were subendocardial hæmorrhage in the left ventricle. The air passages were filled with dark, blood-stained fluid and the lower lobe of the right lung was dark red, consolidated, and airless, portions? of the affected lobe sinking in water.

Histology.-The tumour destroying the pineal glant. had the microscopic structure of a pinealoma of the adult type, being composed of the two kinds of cells: normally found in the fully developed pineal gland Figs. 4 and 5 demonstrate these features.

The cervical tumour closely resembled the pineas growth. The two distinct cell types were present: (Fig. 6), the larger having vesicular nuclei and pale cytoplasm and the smaller dark-staining nuclei closelø resembling lymphocytes. These latter cells were mainle in broad trabeculæ of loosely knit connective tissue which. supported the thin-walled blood vessels. The large nuclei were rather more pleomorphic than in the pinear tumour and more of the small dark cells were lying freg amongst the larger type than in the pineal tumour, which the small cells were mostly confined to the tra? beculæ (Fig. 5). A section of the pedicle of the tumour. (Fig. 7) showed that there was infiltration within the sheath of the spinal nerve as well as alongside it.

Careful macroscopic dissection and multiple his logical examinations failed to reveal any other tumsur deposits in the neuraxis or its membranes.

The consolidated portion of the right lung show advanced hypostatic pneumonia.

$\bullet$

\section{Discussion}

The clinical course of the disease and the phys findings led to the diagnosis of a dumb-bell tumour in the cervical region causing spinal-cord comprese sion. Laminectomy was undertaken as an emers gency procedure because of sudden respirator $\overline{\mathscr{Q}}$ failure. During the illness there were no signs of symptoms which suggested the presence of the primary lesion in the pineal region.

At the time of the operation histological examina tion of a piece of spinal tumour by frozen sectio did not lead to the correct diagnosis. Large celi with vesicular nuclei were seen, together with wht were taken to be lymphocytes, and the appearance was thought to suggest a reticulum cell sarcoma although it was realized that the site was unusuar. After the true nature of the lesion had beew discovered at autopsy and the frozen section re examined, it had to be admitted that the correc $\Phi$ diagnosis might well have been made had it been considered in the differential diagnosis at the time:

Globus and Silbert (1931) have described pineat rests in the quadrigemminal plate, and Russell (1944) two cases with rests in the infundibular region, but no mention of them can be found in the spinal cords It may be possible for the spinal tumour in this case 
Fir. 1. Ihe medlal aspect of the light corebral hemisphere. The pinealoma cut in the saggital plane can be seen as a mottled greyish tumour in the position normally occupied by the pincal gland.

1.16. 2.....The cervical cord fiom the dorsal aspect. The cord is compressed by the tumour, most of which can be seen to be intradural. The pale oval extradural portion is the cut pedicle which passed through the intervertebral foramen of the fourth cervical nerve.

Fici. 3.-The anterior aspect of the extramedullary portion of the cervical tumour. The pedicle of the t umour emerging firom the intervertebral foramen of the fourth cervical nerve can be seen. The neighbouring spinal nerves have been dissected out, excepi the fourth cervical, which is incorporated in the pedicle.

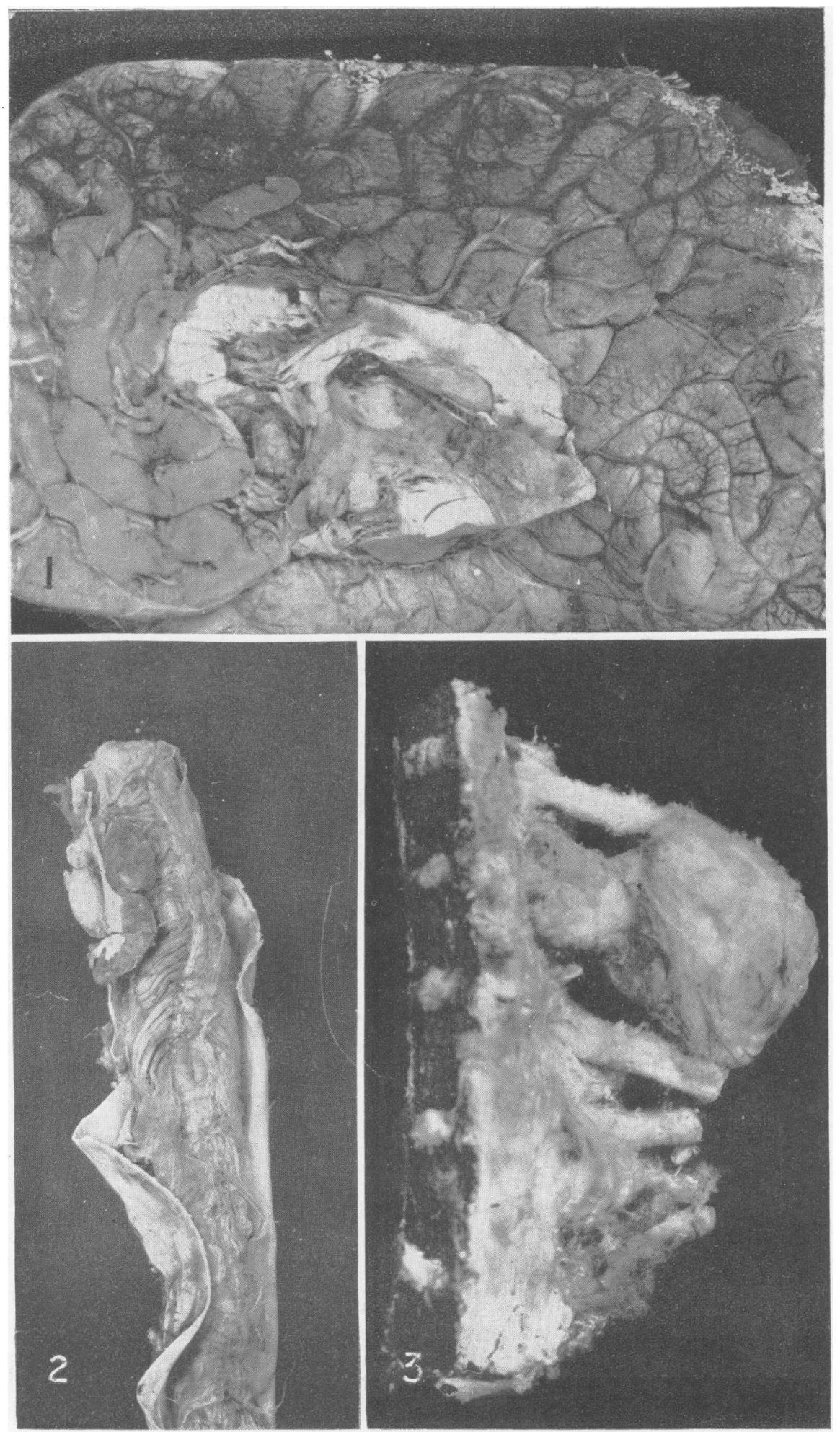




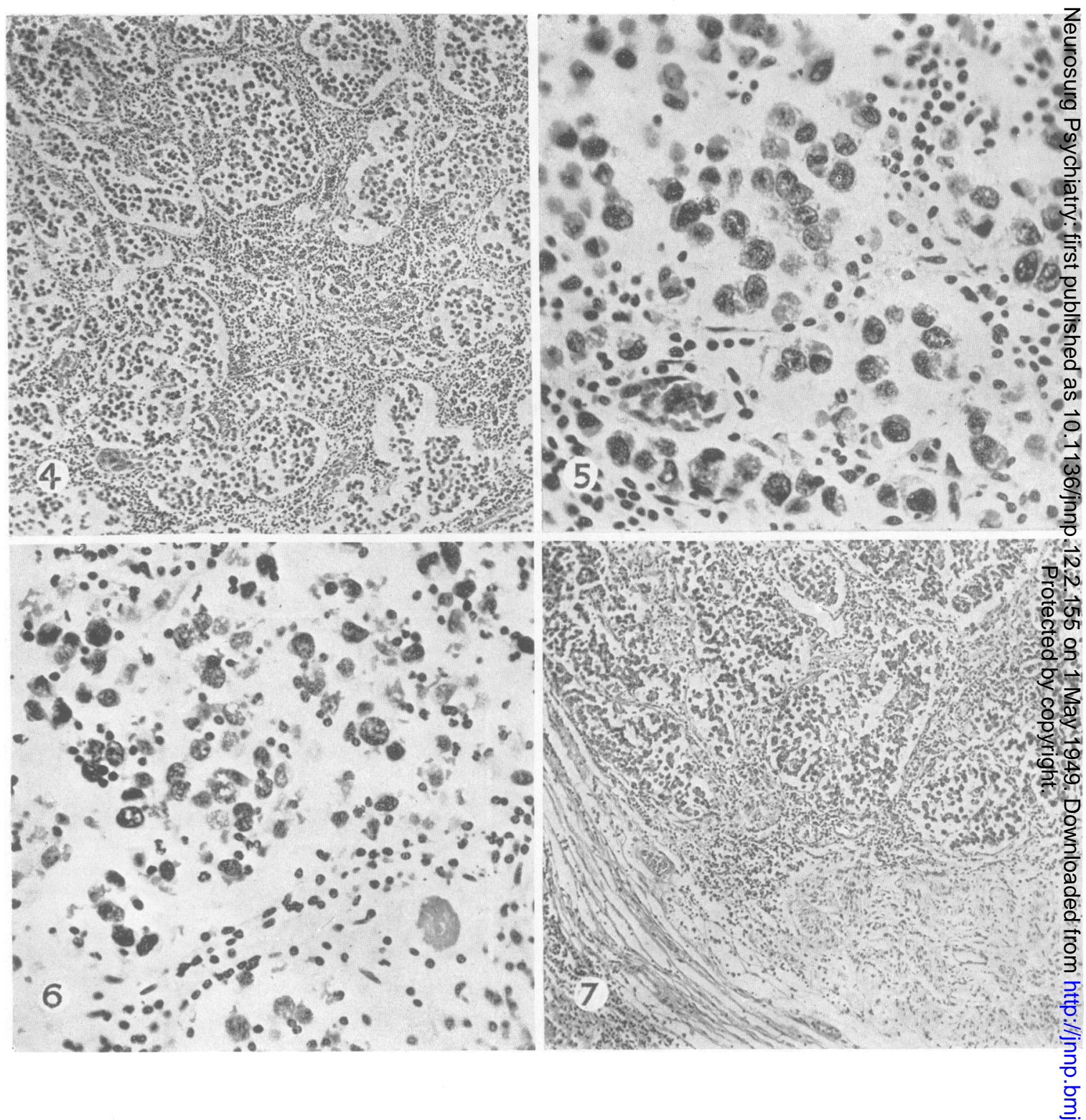

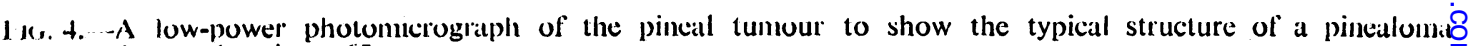
(Hiemalum and eosin, $:$ 65).

Fk(i. 5. - The same as Fig. 4 but at a higher magnitication. The large parenchyma cells are lying in gioups surroundec $\stackrel{\circ}{P}$ by delicate connective tissue in which are the smaller darkly staining cells and blood vessels $(\times 320)$. 1. 16. 6.-A photomicrograph of the spinal tumour to show the similarity to Fig. 5. The parenchyma cells are slightly
more pleomorphic and there are more small dark cells lying free amongst the larger cells $(\times 320)$.

1.1G. 7.-A section through the pedicle of the spinal tumour to show invasion along the nerve, both within the sheath ${ }_{0}$ and outside it. The sheath can be seen on the left, and part of the surviving nerve in the lower right corner $(\times 65), \omega$ 
to have arisen from a rest, but the presence of a true pinealoma as well makes it almost certain that the cervical tumour was a metastasis from the primary tumour in the brain.

\section{Summary}

A case of pinealoma with a solitary spinal metastatis causing cord compression and forming a dumb-bell tumour is described.

The primary tumour gave no clinical signs or symptoms and was discovered only at necropsy.

\section{REFERENCES}

Baggenstoss, A. H., and Love, J. G. (1939). Arch. Neurol. Psychiat., Chicago, 41, 1187.

Ford, F. R., and Muncie, W. (1938). Ibid., 39, 82.

Friedman, E. D., and Plaut, A. (1935). I Ibid., 33, 1324. FuIton, J. F., and Bailey, P. (1929). J. Nerv. Ment. Dis., $69,1,145$ and 261.

Globus, J. H., and Silbert, S. (1931). Arch. Neurol. Psychiat., Chicago, 25, 937.

Horrax, G., and Bailey, P. (1925). Ibid., 13, 423.

Polmeteer, F. E., and Kernohan, J. W. (1947). Ibid., $57,593$.

Russell, D. S. (1944). J. Path. Bact., 56, 145.

Stringer, S. W. (1933). Yale J. Biol. Med., 6, 375.

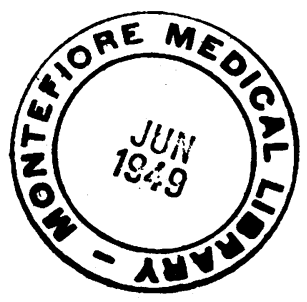

